\title{
A new look for the BJGP
}

Last year we celebrated 50 years of continuous publication of the British Journal of General Practice by the Royal College of General Practitioners. At the same time we concluded a lengthy review of the function and form of the Journal, which included a detailed option appraisal of how and where it should be published. We decided to retain in-house publication, and also to make some changes, which you will see in the May issue of the BJGP.

Our plans for the future of the Journal were informed by a number of considerations. First was our continuing commitment to the central importance of publishing a core of high-quality, peerreviewed original papers relevant to research, education, policy, and practice in primary care. Second was a strong desire to make this research content as accessible as possible to readers from a range of professional backgrounds and, to achieve this, we have introduced a paper short: web long publishing strategy which will be fully implemented next month. This means that the print Journal will include two-page summaries, written by the authors, of full research papers, which we will post online as fully citeable publications as soon as possible after acceptance and sub-editing.

The third consideration was a clear need to respond to readers' views about the appearance and 'feel' of the Journal, and to improve them. To achieve this we have worked closely with our designers and printers and taken advice from a range of colleagues, including the BJGP Editorial
Board, to re-design the Journal to include a number of new features, which we think will make it more attractive and approachable these include a new look for the front cover and the publication highlights, colour coding of Journal sections to help navigation, new paper, chosen with due regard to carbon and sustainability characteristics, and more use of illustrations and photographs. We are reorganising some of the content - such as moving the Back Pages further forward into the Journal and re-naming them 'The Review' - and adding some new sections, including 'Clinical Intelligence' which will contain summaries of recently-published clinical guidelines, technology reviews, and other developments with direct relevance to clinical practice. We will no longer publish Brief Reports, but will be open to Case Reports which illuminate important topics of general applicability. We will continue to welcome submissions of systematic reviews. The 'Debate and Analysis' section will feature stimulating papers on controversial topics in primary health care.

Finally, we wanted to make sure that the Journal is positioned to lead the debate on policy and practice in primary care, to take a broad and international perspective and to be relevant to primary healthcare workers and researchers outside the UK. We will continue to commission high quality editorials from clinical, academic, and policy leaders from within and beyond the UK and stimulate debate by eliciting opinions on key issues in primary care from diverse healthcare systems. Our recently-formed and extensive International Advisory Board is gradually beginning to contribute to these ambitions and our international reach and influence should increase over time.

In making these decisions and changes other factors have entered into the equation, including the need to continue to increase the bibliometric impact of the BJGP in terms of its Impact Factor and other citation indices, while striving to achieve readability and relevance to members and fellows of the RCGP, for whom we are their 'house journal'. The continuing need to develop and expand the online Journal demonstrates how digital technology can help in disseminating journal content, particularly in countries with limited resources. This also helps us to see how the $B J G P$ will link in the future with other RCGP online publications in the fields of continuing professional development and revalidation, will gradually incorporate more sophisticated communication technologies such as apps and podcasting, and will be able to realise commercial opportunities linked to its web presence.

We are already able to offer authors a review and editorial decision service that is faster than most comparable publications and we plan to reduce our acceptance to publication times significantly in the future. This means that readers too will benefit by the increased timeliness, and thereby relevance, of publication in the BJGP, making it something which we hope all our present and potential readers will look forward to opening, either in the post on a Saturday morning or anytime and anywhere in the cybersphere.

\section{Roger Jones \\ Editor BJGP}

DOI: 10.3399/bjgp11X566992

\section{ADDRESS FOR CORRESPONDENCE}

\section{Roger Jones}

Editor, British Journal of General Practice, Royal College of General Practitioners, 1 Bow Churchyard, London EC4 9DQ. E-mail: journal@rcgp.org.uk 